\title{
First Description of a Patient With Vici Syndrome Due to A Mutation Affecting the Penultimate Exon of EPG5 and Review of the Literature ${ }^{\dagger}$
}

\section{Nadja Ehmke, ${ }^{1}$ Nima Parvaneh, ${ }^{2,3}$ Peter Krawitz, ${ }^{1,4,5}$ Mahmoud-Reza Ashrafi, ${ }^{2}$ Parviz Karimi, ${ }^{2}$ Mehrzad Mehdizadeh, ${ }^{6}$ Ulrike Krüger, ${ }^{1}$ Jochen Hecht, ${ }^{1,4,5}$ Stefan Mundlos, ${ }^{1,4,5}$ and Peter N. Robinson ${ }^{1,4,5,7 *}$}

\author{
${ }^{1}$ Institute of Medical and Human Genetics, Charité-Universitätsmedizin Berlin, Berlin, Germany \\ ${ }^{2}$ Department of Pediatrics, Children's Medical Center, Tehran University of Medical Sciences, Tehran, Iran \\ ${ }^{3}$ Research Center for Immunodeficiencies, Tehran University of Medical Sciences, Tehran, Iran \\ ${ }^{4}$ Berlin Center for Regenerative Therapies (BCRT), Charité-Universitätsmedizin Berlin, Berlin, Germany \\ ${ }^{5}$ Max Planck Institute for Molecular Genetics, Berlin, Germany \\ ${ }^{6}$ Radiology Division, Children's Medical Center, Tehran University of Medical Sciences, Tehran, Iran \\ 'Institute for Bioinformatics, Department of Mathematics and Computer Science, Freie Universität Berlin, Berlin, Germany
}

Manuscript Received: 5 February 2014; Manuscript Accepted: 3 July 2014

Vici syndrome is a rare autosomal recessively inherited multisystem disorder characterized by agenesis of the corpus callosum, cataracts, cardiomyopathy, combined immunodeficiency, psychomotor delay, and hypopigmentation. Cullup et al. recently identified mutations in the gene EPG5 as the cause of Vici syndrome. EPG5 is involved in autophagy, an evolutionarily conserved lysosomal degradation process that is essential for cell homeostasis. Following the first description in 1988 by Vici et al., 24 other cases of Vici syndrome have been published with variable expression of the defining features. Here, we report on a further case of Vici syndrome with a homozygous truncating mutation of EPG5, identified by whole-exome sequencing. The mutation in our patient is the first reported affecting the penultimate exon of EPG5 and presenting with typical clinical manifestations of Vici syndrome. Additionally, we present a detailed clinical analysis of Vici syndrome comprising all cases previously described in the literature. ๑ 2014 Wiley Periodicals, Inc.

Key words: agenesis of the corpus callosum, autophagy; cardiomyopathy; developmental delay; EPG5; immunodeficiency; hypopigmentation; Vici syndrome; whole-exome sequencing

\section{INTRODUCTION}

Vici syndrome is a rare autosomal recessively inherited multisystem disorder characterized by agenesis of the corpus callosum, cataracts, cardiomyopathy, combined immunodeficiency, psychomotor delay, and hypopigmentation [del Campo et al., 1999; Dionisi Vici et al., 1988]. Affected individuals often additionally present with microcephaly, failure to thrive, nystagmus, and dysmorphic features. Mutations in the gene EPG5 were recently shown to be causative for Vici syndrome [Cullup et al., 2013]. EPG5 is involved

\section{How to Cite this Article:}

Ehmke N, Parvaneh N, Krawitz P, Ashrafi M-R, Karimi P, Mehdizadeh M, Krüger U, Hecht J, Mundlos S, Robinson PN. 2014. First description of a patient with Vici syndrome due to a mutation affecting the penultimate exon of EPG5 and review of the literature.

Am J Med Genet Part A 164A:3170-3175.

in autophagy and is predominantly expressed in CNS, heart and skeletal muscle, immune cells, lungs, liver, and kidneys. Autophagy is an evolutionarily conserved lysosomal degradation process, essential for cell homeostasis [Mizushima et al., 2008]. It plays a major role in cellular protection processes and is induced by starvation and stress. Impairments of autophagy have been shown to be associated with hereditary disorders such as Danon, Parkinson, Alzheimer, and Huntington disease as well as amyotrophic

Conflict of interest: The authors declare no conflict of interest.

${ }^{\dagger}$ This article was published online on 20 October 2014. Errors were subsequently identified in Table I. The corrected table is shown here.

${ }^{*}$ Correspondence to:

Peter N. Robinson, Institute of Medical and Human Genetics CharitéUniversitätsmedizin Berlin, Augustenburger Platz 1, Berlin 13353, Germany.

E-mail: peter.robinson@charite.de

Article first published online in Wiley Online Library

(wileyonlinelibrary.com): 20 October 2014

DOI 10.1002/ajmg.a.36772 
lateral sclerosis [Aki et al., 2013]. Following the first description in 1988 in two brothers [2], 24 other cases of Vici syndrome have been published with variable expression of the defining features [Chiyonobu et al., 2002; Miyata et al., 2007; Al-Owain et al., 2010; McClelland et al., 2010; Rogers et al., 2011; Finocchi et al., 2012; Ozkale et al., 2012; Said et al., 2012; Cullup et al., 2013]. We report on a boy with Vici syndrome and a novel homozygous truncating mutation of EPG5. The mutation in our patient is the first reported affecting the penultimate exon of EPG5 and presenting with typical clinical manifestations of Vici syndrome. We present a detailed clinical analysis of Vici syndrome comprising all cases previously described in the literature.

\section{CLINICAL REPORT}

We investigated a patient who presented with typical clinical manifestations of Vici syndrome and was referred for evaluation to the Department of Pediatrics of Children's Medical Center, Tehran University of Medical Sciences, Tehran, Iran. The patient was the second child born to healthy consanguineous Iranian parents. His older sister was healthy. The family history was otherwise unremarkable. He was born by Caesarean at 38 weeks gestation following a normal pregnancy. His birth weight was $2.7 \mathrm{~kg}$ and his head circumference (HC) was $34 \mathrm{~cm}$. He first came to attention aged two months with truncal hypotonia and poor feeding. He had light, fair hair, however his parents were darkhaired (Fig. 1). He did not smile, fix or follow and there was a head lag. Lower extremities were spastic. His weight was $3.75 \mathrm{~kg}(<2 \mathrm{SD})$, his height was $51 \mathrm{~cm}(<2 \mathrm{SD})$ and his HC $35 \mathrm{~cm}(<2 \mathrm{SD})$. He had a depressed nasal bridge and micrognathia. Ophthalmologic exam confirmed bilateral macular atrophy. By three months of age, his feeding and respiratory condition deteriorated. He was admitted to PICU after apnea and altered consciousness necessitated mechanical ventilation. During follow up, he was less responsive to external stimuli, became hypotonic and tendon reflexes were lost. The parents declined palliative care and finally he died at the age of 3.5 months after respiratory failure.

Hematologic investigations indicated mild neutropenia and normal lymphocyte and $\mathrm{T}$ cell subset numbers. The bone marrow study was normal. Immunoglobulin G (IgG) levels were lower than normal; however, anti-tetanus and anti-diphtheria antibody responses were in the normal range. Liver function tests showed elevated alanine transferases. CPK and aldolase were raised while troponin I was normal. Lactate dehydrogenase was also raised. Metabolic screening and cerebrospinal fluid analysis were normal. Cardiac echocardiography showed mild hypertrophic cardiomyopathy. Brain computed tomographic scan revealed complete agenesis of the corpus callosum and cerebellar atrophy. Electroencephalography (EEG) performed at the age of three months showed no epileptic activity. Vici syndrome was diagnosed in this patient as he presented the cardinal features callosal agenesis, hypopigmentation, cardiomyopathy, psychomotor delay, and infections.

\section{MATERIALS AND METHODS}

Whole-exome sequencing (WES) was performed on DNA samples of the family trio (Proband 1 and his parents). The study was

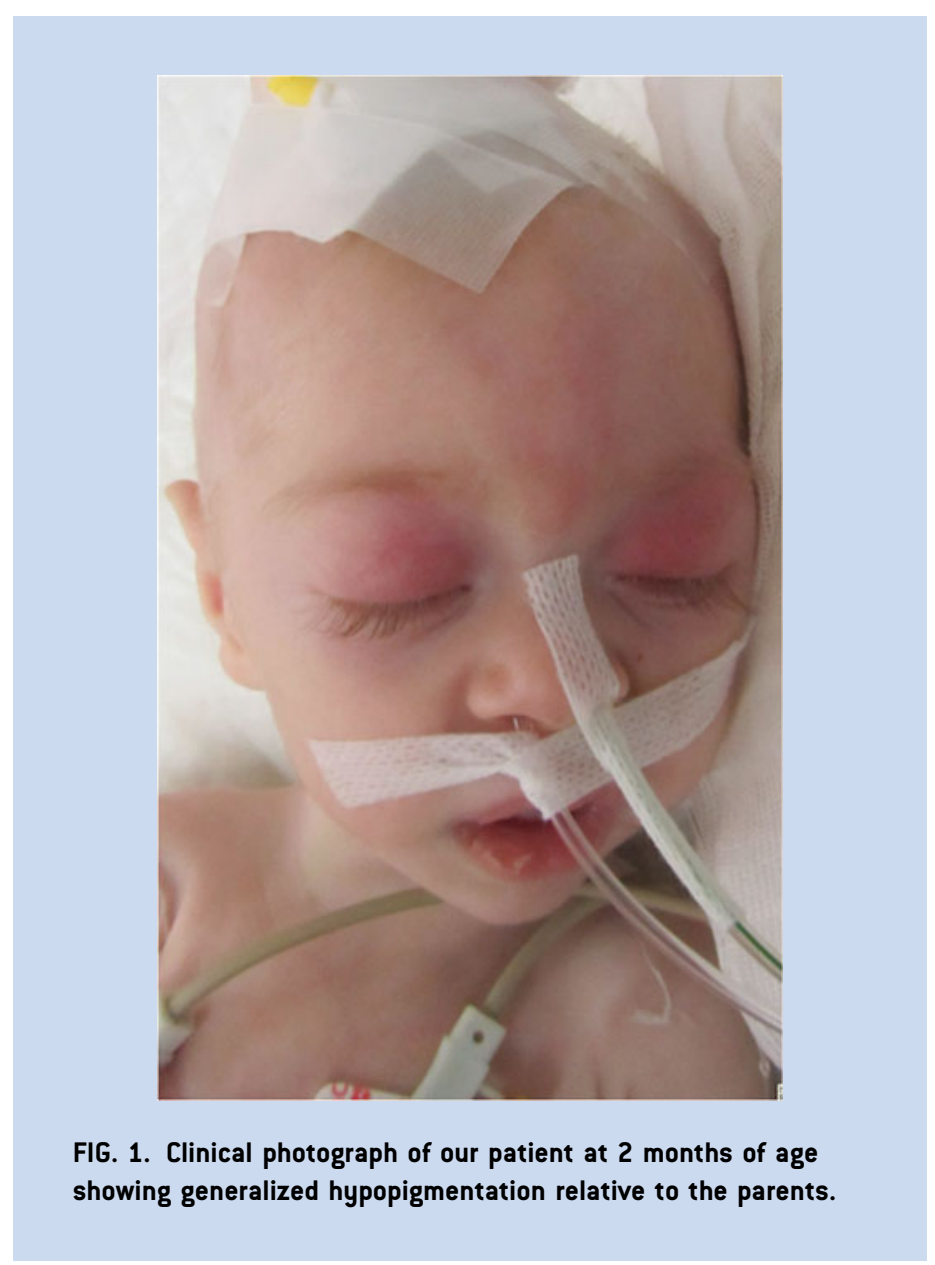

approved by the institutional review board of the Charite. The parents of the affected child gave their written consent for genetic testing and publication of images. Each DNA sample was captured using SureSelect Human All Exon Kit V2 (Agilent), and sequencing of $100 \mathrm{bp}$ paired-end reads was carried out on a HiSeq 2500 (Illumina, San Diego, CA). Sequence reads were mapped to the haploid human reference genome (hg19) using Novoalign (Novoalign, Novocraft; Selangor, Malaysia). Single nucleotide variants (SNVs) and short insertions and deletions (indels) were called using SAMtools and resulted in a high-quality exome variant set [Li, 2011; Heinrich et al., 2013]. The Variant annotation on a functional level was performed using Annovar [Wang et al., 2010]. Sequence variants were filtered for a recessive mode of inheritance (homozygous and compound heterozygous) and for de novo mutations in GeneTalk to identify candidate mutations [Kamphans and Krawitz, 2012]. All candidate mutations were validated by ABI Sanger sequencing PCR and sequencing primers are available upon request.

\section{RESULTS}

The DNA of the patient was subjected to whole-exome sequencing as the molecular cause of Vici syndrome wasn't known at that point of time. As this study was being performed, Cullup et al. [2013], identified EPG5 as the disease causing gene in Vici syndrome in a 
cohort of 18 patients. Filtering for homozygous candidate mutations in GeneTalk yielded 130 mutations, including a previously undescribed nonsense mutation in EPG5, NM_020964.2:c.7447C > T. This variant was also ranked in first place when the phenotypic information was used to rank the candidate genes [Köhler et al., 2009]. The homozygous single base pair substitution in EPG5 results in a premature stop codon in the penultimate exon, p. $\left(\operatorname{Arg} 2483^{*}\right)$, and is predicted to cause nonsense mediated decay.

\section{DISCUSSION}

Following the first description in 1988 by Vici et al. [1988] in two brothers, 24 other cases of Vici syndrome have been published with variable expression of the clinical features [Al-Owain et al., 2010; Chiyonobu et al., 2002; Cullup et al., 2013; del Campo et al., 1999; Dionisi Vici et al., 1988; Finocchi et al., 2012; McClelland et al., 2010; Miyata et al., 2007; Ozkale et al., 2012; Rogers et al., 2011; Said et al., 2012]. We summarize the clinical features of the 26 previously reported cases, along with our own, in Table I.

All patients reported so far, including our own case, presented with agenesis of the corpus callosum, severe psychomotor developmental delay, and a variable degree of hypopigmentation. For 18 patients additional brain abnormalities were documented, the most common of which was cerebellar hypoplasia, also present in our patient.

Twenty-four of 27 patients presented with recurrent infections, which can be assessed as a sign of immunodeficiency. An important issue to consider is that bronchopulmonary infections, which affected many of the patients, also can be due to severe hypotonia. Muscular hypotonia was reported for 16 patients. Four patients showed severe dysphagia, requiring gastric tube feeding [Miyata et al., 2007; Al-Owain et al., 2010; Finocchi et al., 2012]. Thus, it is not always possible to know whether the cause of the recurrent infections was immunodeficiency. Muscular hypotonia was especially truncal and often combined with hypertonic and flexed lower limbs. Elevated muscle enzymes in some patients suggest a muscular etiology of hypotonia. Myopathy was confirmed by muscle biopsy for nine patients, including two of the patients with elevated muscle enzymes. One patient had hypotonia but no abnormalities observable by muscle biopsy [Rogers et al., 2011]. Thus, skeletal myopathy is not a constant feature of Vici syndrome and muscular hypotonia cannot always be attributed to myopathy.

Cardiomyopathy is an important characteristic of Vici syndrome. There are only four patients reported without cardiac involvement. All of them were alive by the time of the publication, indicating that cardiomyopathy is an important mortality factor in Vici syndrome.

Cataract is common in Vici syndrome. Three of the patients without cataract died in the first year of life, including our own case. Therefore, we cannot exclude that cataract would have developed had the patient survived. Other ocular manifestations are listed in Table I.

Further common features are congenital or postnatal microcephaly, growth retardation and facial dysmorphism, most frequently in the shape of a high arched palate and micrognathia. Features only presented by a small number of patients are renal tubular acidosis, laryngomalacia, atrial septal defect, hypospadia, lung hypoplasia, and severe scoliosis. One affected girl was delivered at the 33rd week of gestation and later presented with spastic quadriplegia, which can be due to preterm delivery.

Cullup et al., recently showed mutations in the gene EPG5 to be causative for Vici syndrome [Cullup et al., 2013]. They identified 20 different mutations of EPG5 in a cohort of 18 affected individuals (Fig. 2). In two affected individuals, no disease causing mutation in EPG5 could be identified, indicating the possibility of locus heterogeneity [Cullup et al., 2013].

EPG5 consists of 44 exons, and the longest transcript encodes a protein of 2,579 amino acids. The mutations identified by Cullup et al. [2013] are spread over almost the entire gene, distributed between exons 2 and 39. The mutation in our patient is located in exon 43, probably leading to nonsense-mediated decay. An mRNA specimen from the patient was not available. So far, knowledge about EPG5 is scant. The only known domain of EPG5 is a coiledcoil domain, spanning codon 1607-1633 and containing none of the disease causing mutations. Multiple transcripts of EPG5 are listed in Ensembl [Flicek et al., 2014]. The longest, corresponding to NM_020964.2, is the only one that contains all reported disease causing mutations of EPG5. Thus, Vici syndrome is largely due to defects of the longest transcript.

EPG5 is involved in autophagy, an evolutionarily conserved lysosomal degradation process, essential for cell homeostasis. Besides recycling cytoplasmic material during periods of starvation or stress, autophagy clears protein aggregates, eliminates pathogens and influences cell death [Mizushima et al., 2008]. Tian et al. studied the autophagy pathway in C. elegans and identified for the first time EPG5 as essential for the degradation step of starvation-induced autophagy [Tian et al., 2010]. Cullup et al. measured a strong upregulation of sarcomere-associated autophagy proteins in skeletal muscle tissue from two affected individuals, indicating a block in the autophagy pathway [Cullup et al., 2013]. Their results indicate a severe deficit in autophagosomal clearance associated with mutations in EPG5, resulting in the accumulation of autophagic cargo and the impaired fusion with lysosomes.

Impaired autophagy has been linked to cardiomyopathy, myopathy, neurodegeneration, immune dysfunction, pigmentary defects, oncogenesis, and disturbed embryonic development [Nishino et al., 2000; Fimia et al., 2007; Nakai et al., 2007; Di Bartolomeo et al., 2010; Taneike et al., 2010; Levine et al., 2011; Choi et al., 2013], but our understanding of how the process contributes to pathogenesis is incomplete. For instance, the role of impaired autophagy in congenital cataract remains unclear. Dysfunction of ATG5, required for autophagosome formation, has been found to be involved in age-related cataract in mice. However, there is no primary involvement of conventional autophagy in programmed organelle degradation in the lens and thus defective autophagy probably does not cause congenital cataract in mice [Morishita et al., 2013]. In contrast, homozygous mutations in FYCO1 gene, playing a role in the transport of autophagic vesicles, cause congenital cataract in humans [Chen et al., 2011]. Further investigations of the role of autophagy in the human lens will be required to clarify the role of autophagocytic defects in the pathogenesis of cataract.

Zhao et al. recently proved that EPG5-deficient mice presented some but not all phenotypic similarities with Vici syndrome 


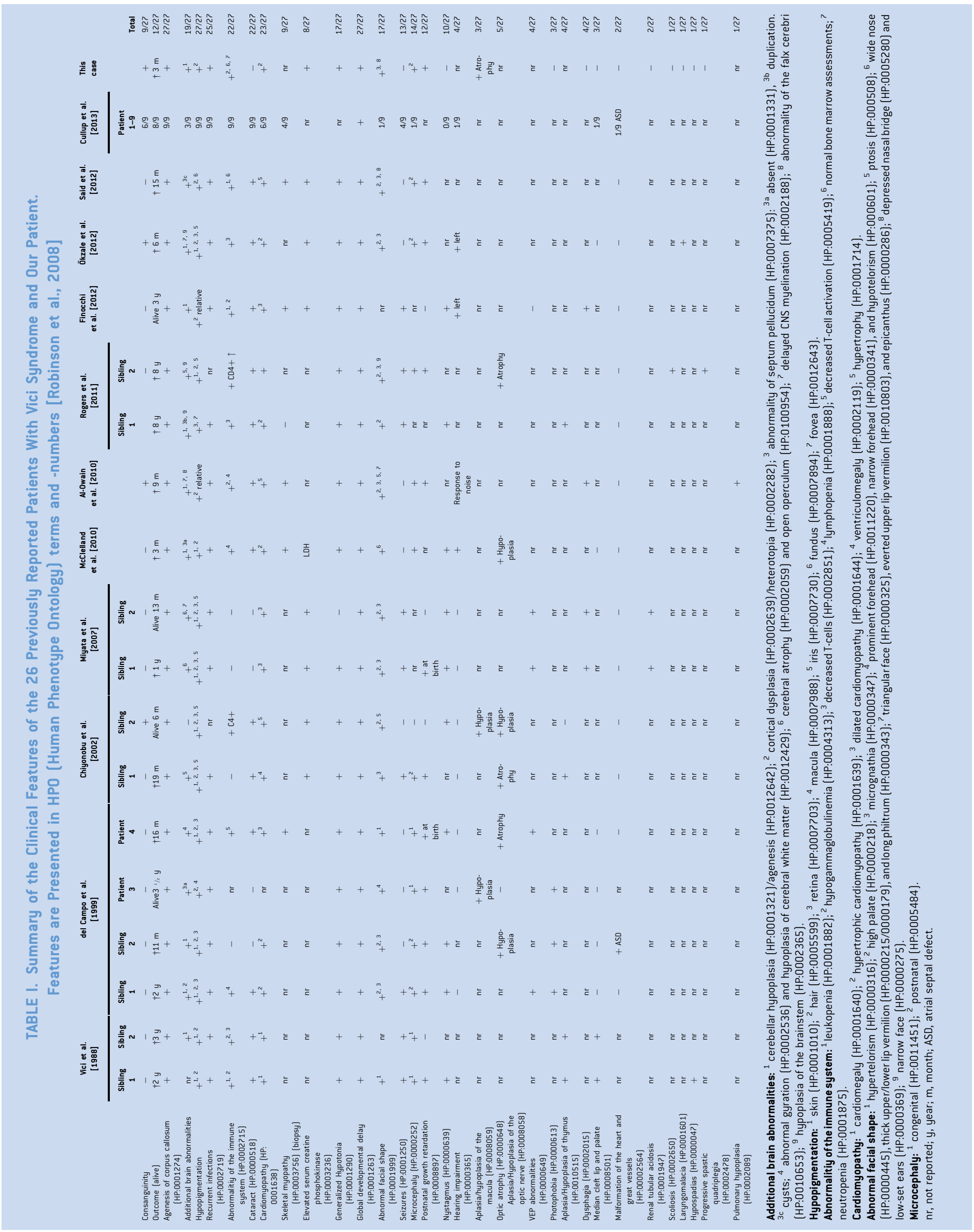




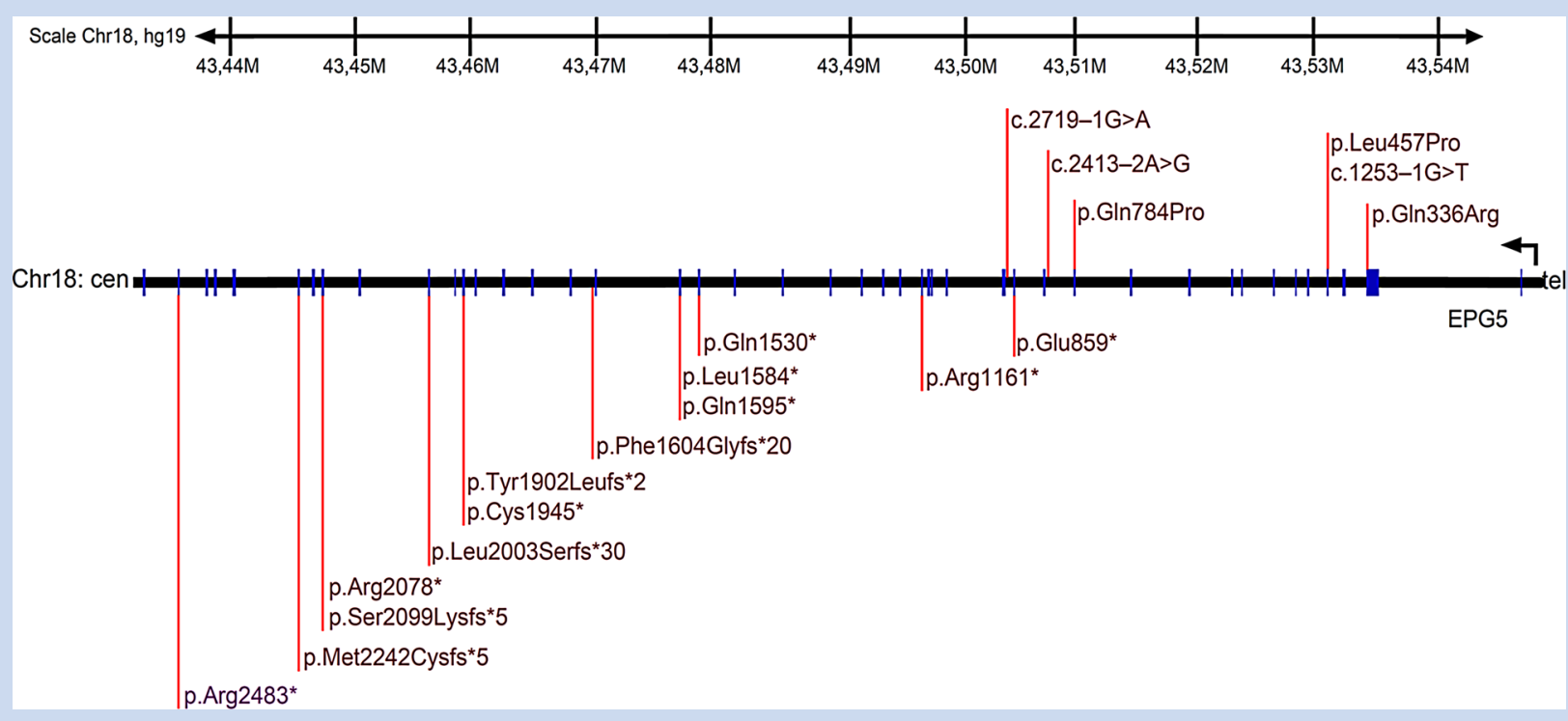

FIG. 2. Schematic diagram of EPG5 gene, which is located on the Crick strand of chromosome 18, showing the location of the truncating mutation identified in our patient in violet (p.Arg2483*) as well as previously described missense and truncating mutations [Cullup et al., 2013] in red. Missense mutations are shown above and truncating mutations below the black bar.

patients including corpus callosum changes and myopathy [Zhao et al., 2013]. However, many features of Vici syndrome, including hypopigmentation and facial dysmorphism, were absent. Interestingly, EPG5-deficient mice also did not show cataract, however they only survived until the age of 10 to 12 months. Thus, it is possible that cataract would have developed later in life. There were also no signs of immunodeficiency, but these mice were raised under specific pathogen-free conditions in a low-stress environment. Another possible explanation for the differing phenotype could also be a distinct expression pattern of EPG5 in mice.

In conclusion, Vici syndrome is a rare autosomal recessive multisystem disease, recently shown to be caused by mutations in EPG5. The underlying pathomechanism is a defect in autophagy, a highly conserved mechanism involved in cell homeostasis. The complete understanding of the role of EPG5 in the autophagy pathway and the pathophysiology of Vici syndrome needs further investigations. Our patient is the first described carrying a mutation in the penultimate exon of EPG5.

\section{REFERENCES}

Aki T, Funakoshi T, Unuma K, Uemura K. 2013. Impairment of autophagy: From hereditary disorder to drug intoxication. Toxicology 311:205-215.

Al-Owain M, Al-Hashem A, Al-Muhaizea M, Humaidan H, Al-Hindi H, Al-Homoud I, Al-Mogarri I. 2010. Vici syndrome associated with unilateral lung hypoplasia and myopathy. Am J Med Genet A 152A: 1849-1853.

Chen J, Ma Z, Jiao X, Fariss R, Kantorow WL, Kantorow M, Pras E, Frydman M, Pras E, Riazuddin S, Riazuddin SA, Hejtmancik JF. 2011. Mutations in FYCO1 cause autosomal-recessive congenital cataracts. Am J Hum Genet 88:827-838.
Chiyonobu T, Yoshihara T, Fukushima Y, Yamamoto Y, Tsunamoto K, Nishimura Y, Ishida H, Toda T, Kasubuchi Y. 2002. Sister and brother with Vici syndrome: Agenesis of the corpus callosum, albinism, and recurrent infections. Am J Med Genet 109:61-66.

Choi AM, Ryter SW, Levine B. 2013. Autophagy in human health and disease. N Engl J Med 368:651-662.

Cullup T, Kho AL, Dionisi-Vici C, Brandmeier B, Smith F, Urry Z, Simpson MA, Yau S, Bertini E, McClelland V, Al-Owain M, Koelker S, Koerner C, Hoffmann GF, Wijburg FA, ten Hoedt AE, Rogers RC, Manchester D, Miyata R, Hayashi M, Said E, Soler D, Kroisel PM, Windpassinger C, Filloux FM, Al-Kaabi S, Hertecant J, Del Campo M, Buk S, Bodi I, Goebel $\mathrm{HH}$, Sewry CA, Abbs S, Mohammed S, Josifova D, Gautel M, Jungbluth H. 2013. Recessive mutations in EPG5 cause Vici syndrome, a multisystem disorder with defective autophagy. Nat Genet 45:83-87.

del Campo M, Hall BD, Aeby A, Nassogne MC, Verloes A, Roche C, Gonzalez C, Sanchez H, Garcia-Alix A, Cabanas F, Escudero RM, Hernandez R, Quero J. 1999. Albinism and agenesis of the corpus callosum with profound developmental delay: Vici syndrome, evidence for autosomal recessive inheritance. Am J Med Genet 85:479-485.

Di Bartolomeo S, Nazio F, Cecconi F. 2010. The role of autophagy during development in higher eukaryotes. Traffic 11:1280-1289.

Dionisi Vici C, Sabetta G, Gambarara M, Vigevano F, Bertini E, Boldrini R, Parisi SG, Quinti I, Aiuti F, Fiorilli M. 1988. Agenesis of the corpus callosum, combined immunodeficiency, bilateral cataract, and hypopigmentation in two brothers. Am J Med Genet 29:1-8.

Fimia GM, Stoykova A, Romagnoli A, Giunta L, Di Bartolomeo S, Nardacci R, Corazzari M, Fuoco C, Ucar A, Schwartz P, Gruss P, Piacentini M, Chowdhury K, Cecconi F. 2007. Ambral regulates autophagy and development of the nervous system. Nature 447:1121-1125.

Finocchi A, Angelino G, Cantarutti N, Corbari M, Bevivino E, Cascioli S, Randisi F, Bertini E, Dionisi-Vici C. 2012. Immunodeficiency in Vici syndrome: A heterogeneous phenotype. Am J Med Genet A 158A(2): 434-439. 
Flicek P, Amode MR, Barrell D, Beal K, Billis K, Brent S, Carvalho-Silva D, Clapham P, Coates G, Fitzgerald S, Gil L, Girón CG, Gordon L, Hourlier T, Hunt S, Johnson N, Juettemann T, Kähäri AK, Keenan S, Kulesha E, Martin FJ, Maurel T, McLaren WM, Murphy DN, Nag R, Overduin B, Pignatelli M, Pritchard B, Pritchard E, Riat HS, Ruffier M, Sheppard D, Taylor K, Thormann A, Trevanion SJ, Vullo A, Wilder SP, Wilson M, Zadissa A, Aken BL, Birney E, Cunningham F, Harrow J, Herrero J, Hubbard TJ, Kinsella R, Muffato M, Parker A, Spudich G, Yates A, Zerbino DR, Searle SM. 2014. Ensembl 2014. Nucleic Acids Res 42:D749-755.

Heinrich V, Kamphans T, Stange J, Parkhomchuk D, Hecht J, Dickhaus T, Robinson PN, Krawitz PM. 2013. Estimating exome genotyping accuracy by comparing to data from large scale sequencing projects. Genome Med 5:69.

Kamphans T, Krawitz PM. 2012. GeneTalk: An expert exchange platform for assessing rare sequence variants in personal genomes. Bioinformatics 28:2515-2516.

Köhler S, Schulz MH, Krawitz P, Bauer S, Dolken S, Ott CE, Mundlos C, Horn D, Mundlos S, Robinson PN. 2009. Clinical diagnostics in human genetics with semantic similarity searches in ontologies. Am J Hum Genet $85: 457-464$

Levine B, Mizushima N, Virgin HW. 2011. Autophagy in immunity and inflammation. Nature 469:323-335.

Li H. 2011. A statistical framework for SNP calling, mutation discovery, association mapping and population genetical parameter estimation from sequencing data. Bioinformatics 27:2987-2993.

McClelland V, Cullup T, Bodi I, Ruddy D, Buj-Bello A, Biancalana V, Boehm J, Bitoun M, Miller O, Jan W, Menson E, Amaya L, Trounce J, Laporte J, Mohammed S, Sewry C, Raiman J, Jungbluth H. 2010. Vici syndrome associated with sensorineural hearing loss and evidence of neuromuscular involvement on muscle biopsy. Am J Med Genet A 152A:741-747.

Miyata R, Hayashi M, Sato H, Sugawara Y, Yui T, Araki S, Hasegawa T, Doi S, Kohyama J. 2007. Sibling cases of Vici syndrome: Sleep abnormalities and complications of renal tubular acidosis. Am J Med Genet A 143:189-194.

Mizushima N, Levine B, Cuervo AM, Klionsky DJ. 2008. Autophagy fights disease through cellular self-digestion. Nature 451:1069-1075.

Morishita H, Eguchi S, Kimura H, Sasaki J, Sakamaki Y, Robinson ML, Sasaki T, Mizushima N. 2013. Deletion of autophagy-related 5 (Atg5) and
Pik3c3 genes in the lens causes cataract independent of programmed organelle degradation. J Biol Chem 288:11436-11447.

Nakai A, Yamaguchi O, Takeda T, Higuchi Y, Hikoso S, Taniike M, Omiya S, Mizote I, Matsumura Y, Asahi M, Nishida K, Hori M, Mizushima N, Otsu K. 2007. The role of autophagy in cardiomyocytes in the basal state and in response to hemodynamic stress. Nat Med 13:619-624.

Nishino I, Fu J, Tanji K, Yamada T, Shimojo S, Koori T, Mora M, Riggs JE, Oh SJ, Koga Y, Sue CM, Yamamoto A, Murakami N, Shanske S, Byrne E, Bonilla E, Nonaka I, DiMauro S, Hirano M. 2000. Primary LAMP-2 deficiency causes X-linked vacuolar cardiomyopathy and myopathy (Danon disease). Nature 406:906-910.

Ozkale M, Erol I, Gumus A, Ozkale Y, Alehan F. 2012. Vici syndrome associated with sensorineural hearing loss and laryngomalacia. Pediatr Neurol 47:375-378.

Robinson PN, Kohler S, Bauer S, Seelow D, Horn D, Mundlos S. 2008. The human phenotype ontology: A tool for annotating and analyzing human hereditary disease. Am J Hum Genet 83:610-615.

Rogers RC, Aufmuth B, Monesson S. 2011. Vici syndrome: A rare autosomal recessive syndrome with brain anomalies, cardiomyopathy, and severe intellectual disability. Case Rep Genet 2011:421582.

Said E, Soler D, Sewry C. 2012. Vici syndrome-a rapidly progressive neurodegenerative disorder with hypopigmentation, immunodeficiency and myopathic changes on muscle biopsy. Am J Med Genet A 158A:440444.

Taneike M, Yamaguchi O, Nakai A, Hikoso S, Takeda T, Mizote I, Oka T, Tamai T, Oyabu J, Murakawa T, Nishida K, Shimizu T, Hori M, Komuro I, Takuji Shirasawa TS, Mizushima N, Otsu K. 2010. Inhibition of autophagy in the heart induces age-related cardiomyopathy. Autophagy 6:600-606.

Tian Y, Li Z, Hu W, Ren H, Tian E, Zhao Y, Lu Q, Huang X, Yang P, Li X., et al., 2010. C. elegans screen identifies autophagy genes specific to multicellular organisms. Cell 141:1042-1055.

Wang K, Li M, Hakonarson H. 2010. ANNOVAR: Functional annotation of genetic variants from high-throughput sequencing data. Nucleic Acids Res 38:e164.

Zhao YG, Zhao H, Sun H, Zhang H. 2013. Role of Epg5 in selective neurodegeneration and Vici syndrome. Autophagy 9:1258-1262. 